\title{
Investigation of Register Errors in Iraqi EFL Students' Writings
}

\author{
Lina Lafta Jassim \\ English Department, College of Art, University of Thi-Qar, Nasiriyah, Iraq \\ Email: lfnar83@gmail.com
}

\begin{abstract}
EFL students' writings indicate that stylistic problems are the area of difficulty. In this way, this study is designed to explore register errors in EFL students' writings. The subjects of this study are 40 third-year English Iraqi students at Thi-Qar university. Thus this research aims to indicate stylistic difficulties which Iraqi EFL students face in their English writing, explain the main reasons lead the students to fall in register errors. The study hypothesizes that incompetence in using and writing English appropriately is potentially the major possible source of the registry errors. The second hypothesis is that most Iraqi English students are unable to distinguish between oral and written style. The results of the study indicated most Iraqi EFL students' written performance was similar to their spoken language. They wrote in the same way they spoke.
\end{abstract}

Keywords: Register errors, EFL students, writings, errors analysis.

\section{Introduction}

EFL students face difficulties which lead them to fall in errors. Register errors are one of these errors. These errors happen as a result of mixing different types of register errors in their writing. ALQaraghooly and Sultan (2008:4) emphasize that this problem may be attributed to several reasons, chief among which is the fact that English writing is characterized by some linguistic and stylistic peculiarities which, among other things, add more difficulty to the students.

The difficulty may also be due to the gaps languages manifest in their linguistic structures (Baker, 1992: 100). Accordingly, as English and Arabic are genetically distinct languages showing many linguistic gaps, a lot of mistakes will inevitably result in our students' writing, unless the well- form of English writing is taken into consideration.

\subsection{Definition of Basic Terms}

The basic terms, which are related to the present study, are included in this section.

\subsubsection{Error}

An error is "a deviation in learner language which results from lack of knowledge of the correct rule" (Corder, 1967 as cited in Ellis, 1994: 700). Corder (1973: 259-60) also defines errors as 'breaches of the code' and refers to them as

"those features of the learner's utterances which differ from those of any native speaker".

\subsubsection{Error analysis}

Error analysis "involves a set of procedures for identifying, describing and explaining errors in learner language" (Ellis, 1994: 701). It provides a comparison of the language of the learner at some particular point in his course with the target language (Corder, 1973: 149).

\subsubsection{Register errors}

It is a stylistic error where different levels of language are mixed. Register is the manner of speaking or writing specific to a certain domain of communication (Vinay and Darbelnay, 1963:21). This way of communicating is determined by how much a writer chooses to distance himself from his reader and topic. Relatively, the term register has been defined by many sociolinguists; for instance, Hudson (1996: 23) defines it as "varieties according to use." in this definition, one can note that register is the way that language use varies according to situations; that each type of register is used to fulfill a type of communication purposes, in order to fit each register to the situation which needs that type of register. We find in the literature four broadly defined registers: Familiar, Informal, Formal and Ceremonial (Al- 
Samarrai, 2003:32). To these very classical registers, we can suggest: the technology and the scientific registers which do have their own internal logic and textual organization. In most languages from Asia, register is often paired with the honorifics level, which then introduces another, orthogonal, register level within the English language academic community, the conventions of formal register are generally followed. The choice of register for a particular text, part of text, or spoken presentation will vary depending on genre and audience, but it is important not to mix registers up (Chuquet and Paillard, 1989:23).

\subsubsection{Style}

According to Richards \& Schmidt $(2002,522)$ style is a "variation in a person's speech or writing". Style similar to register varies from casual to formal according to situations Some linguists use the term 'register' for a stylistic variety. One can note that both terms are similar to each other, but the term style can be considered as more general than register. In other words register is narrower than style (cited in Biber, 1995:9).

\section{Formality \& Informality in English}

Some kinds of writing are always written in formal English (e.g. some kinds of essay). However, some writing is usually informal (e.g. notes). (1) In this way, the EFL students mix different register types in their writing leading them to fall in register errors (Hammadou, 2000:44). Generally, the features of formal English are normally found and more frequently in writing; features of informal English are normally found more frequently in speech. The most common characteristics of EFL student have in their writings are:

\subsection{Imprecise Language}

Many students use long sentences. This leads their writing is difficult to understand. For example:

(1) *The theory is simple, harvest the free light and the heat of the sun, then either directly heat water running through pipes of high heat absorptive through irradiation or convert it into electricity through photovoltaic cells to heat stored water by means of a heating element.

(2) These sentences are incorrectly joined together with commas. Such a long sentence is difficult to understand. However, good English writing contains short clear sentences, e.g., (2)

${ }^{*}$ This character has a proclivity for screwing up everything.

In (2) example, there is register error because of being long and having informal words e.g., "proclivity" and "screwing up".

(3) This character tends to wreck everything.

The sentence above is easy to understand because of being clear and short, (Vinay and et al, 1963:30).

\subsection{Purposefully Vague Language}

This includes very frequent nouns such as thing and stuff and phrases such as I think, I don't know (i.e., expressions of opinions) and personal pronouns:

\subsubsection{Expressions of opinion}

This includes a very frequent use of phrases such as I think, I believe, we argue, etc. which serve to approximate and to make statements less assertive. Similarly, Hearst and Text Tiling (1997) indicate there are a number of forms that need some forms of polishing or care. For example, expression of opinion needs a lot of care. Note the following example which is cited from Prakken (2006):

$(4)^{*}$ I believe NATO's strategy was poorly designed and carelessly implemented.

$(5)^{*}$ We argue that NATO's strategy was poorly designed and carelessly implemented.

(6)* You can see that NATO's strategy was poorly designed and carelessly implemented.

In all the examples above, the student believes that NATO's strategy was poorly designed and carelessly implemented. To increase formality, impersonal structures are required. This can be done in a variety of ways. First, an opinion can be stated directly. It should be obvious what the student believes if she/he writes:

- NATO's strategy was poorly designed and carelessly implemented. 


\subsubsection{Personal pronouns}

This includes the frequent use of personal pronouns, especially $I$ and you and we, often in a contracted form such as I'd or we've. The pronouns I, we and you are not always appropriate in formal written register.

Damen (2002:21) emphasizes that formal language works best when it appears to be impersonal, driven not by opinion but fact. That entails creating distance between the reader and the writer, in that such a posture makes a statement seem more objective.

1. Among other things, objectivity precludes the use of personal pronouns like "you" and "yours" which bring reader and writer into direct contact. This also includes imperative (command) forms which imply "you." Examples of such imperative forms are "Remember how important it is...," "Bear in mind that this is true...," "Take for example..." and "Note the ways in which Sophocles uses character." (ibid)

2. For the same reason, "I/me/my" and "we/us/our" should also be avoided as much as possible. (Devlin and Waters, 2012:10).

For examples:

(7)* You put the chemicals in the test tube.

(8)* We used two different methods research.

However, (7) and (8) examples are incorrect, they should be written in the following forms:

- The chemicals are put in the test tube.

- There were two different methods of research.

\subsection{Clause Structure Which Often Consists of Several Clauses Chained Together}

For example:

(9)*'m sorry but I can't meet you tonight and the cat's ill which doesn't help but call me anyway.

The example above should be written as it follows:

-I cannot meet you tonight because the cat is unfortunately unwell. However, please do call me anyway.

The last form is correct because clause structure does not consist of clauses chained together as in (9) example.

\subsection{Contractions}

Whenever two words are merged into one to form a shortened form, or contraction, the apostrophe indicates the letters skipped in the process of merging. For example formal writing often doesn't use contractions. This means that contractions must be avoided in academic writings.

Examples: can + not $=$ can't

did + not $=$ didn't

$\mathrm{I}+$ will $=$ I'll

it + is $=$ it's

Here are some more: couldn't, wouldn't, shouldn't, hadn't, shan't, don't, could've, would've, should've, etc.

Hammadous' study (2000) emphasizes that register errors also include the need to distinguish between oral style and written style. These two types of writings have their own conventions .In written style, a number of elements of oral style should not be used such as contractions:

(10)* The English Monarchy wasn't responding to the needs of the population.

The example above should be written as it follows:

- The English Government was not responding to the needs of the population.

\subsection{Single Words or Short Phrases Are Used in EFL Students' Writing}

For example: Absolutely, Exactly, I see, No, Yes, Of course, etc. 


\section{Methods of Investigation and Procedures}

In this section, we introduce the methods and procedures are used to achieve the aims of the study.

\subsection{Methods of Investigation}

In order to achieve the aims of this study, several methods are chiefly employed as the descriptive, analytic methods and statistic method. The design of the study is based on the combination of both qualitative and quantitative approaches. The qualitative approach is used in describing and analyzing data to find the frequency and the number of register errors committed in the subjects' writings. On the contrary, the quantitative approach is useful for determining the percentage of these errors. Quantitative analyses are based on the frequencies of register errors occur in the subjects' English writings. Forty third-year students' writings from the Department of English, College of Education for Human Sciences, University of Thi-Qar, of the academic year 2013-2014 are chosen randomly to gather the data of this study. Forty subjects consist of both males and females. It is possible to note that the subjects in this stage are supposed to be highly advanced in a paragraph writing than first -year one.

The data are collected from subjects' written paragraphs. About forty paragraphs collected from 40 students in class are analyzed and statistically indicated. Since the error analysis used in this study focused especially on stylistic errors regardless of other writing skills, such as idea expression, organization, and cohesion, the essay scoring involved error frequency counts for register errors only.

\subsection{Data Analysis}

Five categories are studied to determine how the subjects tend to use them inappropriately. That is, mixing oral elements of the register in their writing. These categories are: (1) First Person Pronoun, (2) Expressions of Pronouns, (3) Clause structure Errors, (4) Contractions, (5) Single words.

Table 1. Types of register errors and number of students' wrong answers

\begin{tabular}{llllll}
\hline \multirow{2}{*}{ N. } & Types of Register Errors & $\begin{array}{l}\text { N. of Students' } \\
\text { Correct Answers }\end{array}$ & Percentage & $\begin{array}{l}\text { N. of Students' } \\
\text { Wrong Answers }\end{array}$ & Percentage \\
\hline 1 & First Person Pronoun & 3 & 7.5 & 37 & 92.5 \\
2 & Expressions of Pronouns & 9 & 22.5 & 31 & 77.5 \\
3 & Clause structure Errors & 11 & 27.5 & 29 & 62.5 \\
4 & Contractions & 16 & 40 & 24 & 60 \\
5 & Single Words & 29 & 62.5 & 11 & 27.5 \\
\hline
\end{tabular}

$\square$ N. of Students' Correct Answers $\quad$ Percentage $\quad$ N. of Students' Wrong Answers $\square$ Percentage

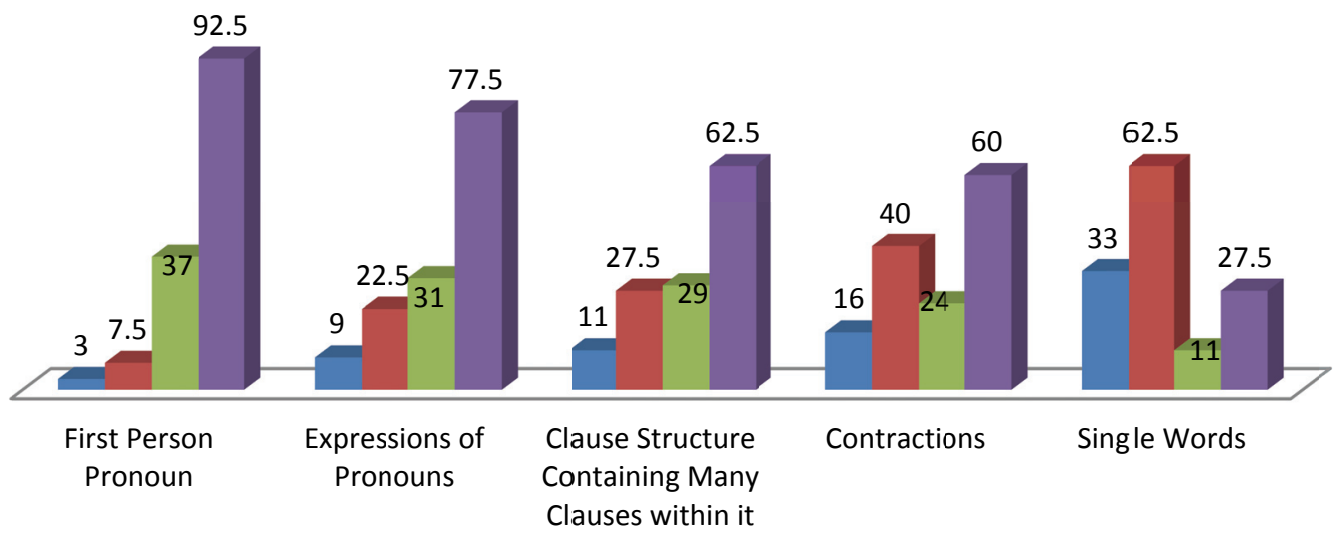

Figure 1. The hierarchical frequency of the students' wrong answers 
Table 1 indicates that the most subjects fall in errors as results of their using first person pronoun in their English writing, that is, (37), i.e., (92,5\%); However, the less number of subjects commit errors for their using single words, that is, (11), i.e., $(27.5 \%)$.

\section{Results}

In this section, the five categories of errors are presented according to their ranking, orders; i.e. beginning with the highest-frequency errors. In addition, samples of the study subjects' errors are provided. Finally, an explanation of errors is attempted.

\subsection{Description of Register Errors}

This section indicates the largest number of errors with a total of 762 errors and a percentage of 99.998 which means that the first hypothesis is verified. It is further divided into many errors as shown in Table 2

Table 2. Frequency and percentages of the register errors in Iraqi EFL students' writing

\begin{tabular}{lccc}
\hline Type of Error & Frequency & Percentage & Rank \\
\hline First Person Pronoun & 261 & 34.251 & 1 \\
Expressions of Pronoun & 187 & 24.540 & 2 \\
Clause Structure Containing Many Clauses within it. & 150 & 19.685 & 3 \\
Contraction & 120 & 15.748 & 4 \\
Single Words & 44 & 5.774 & 5 \\
\hline \multicolumn{2}{c}{ Total } & 762 & 99.998 \\
\hline
\end{tabular}

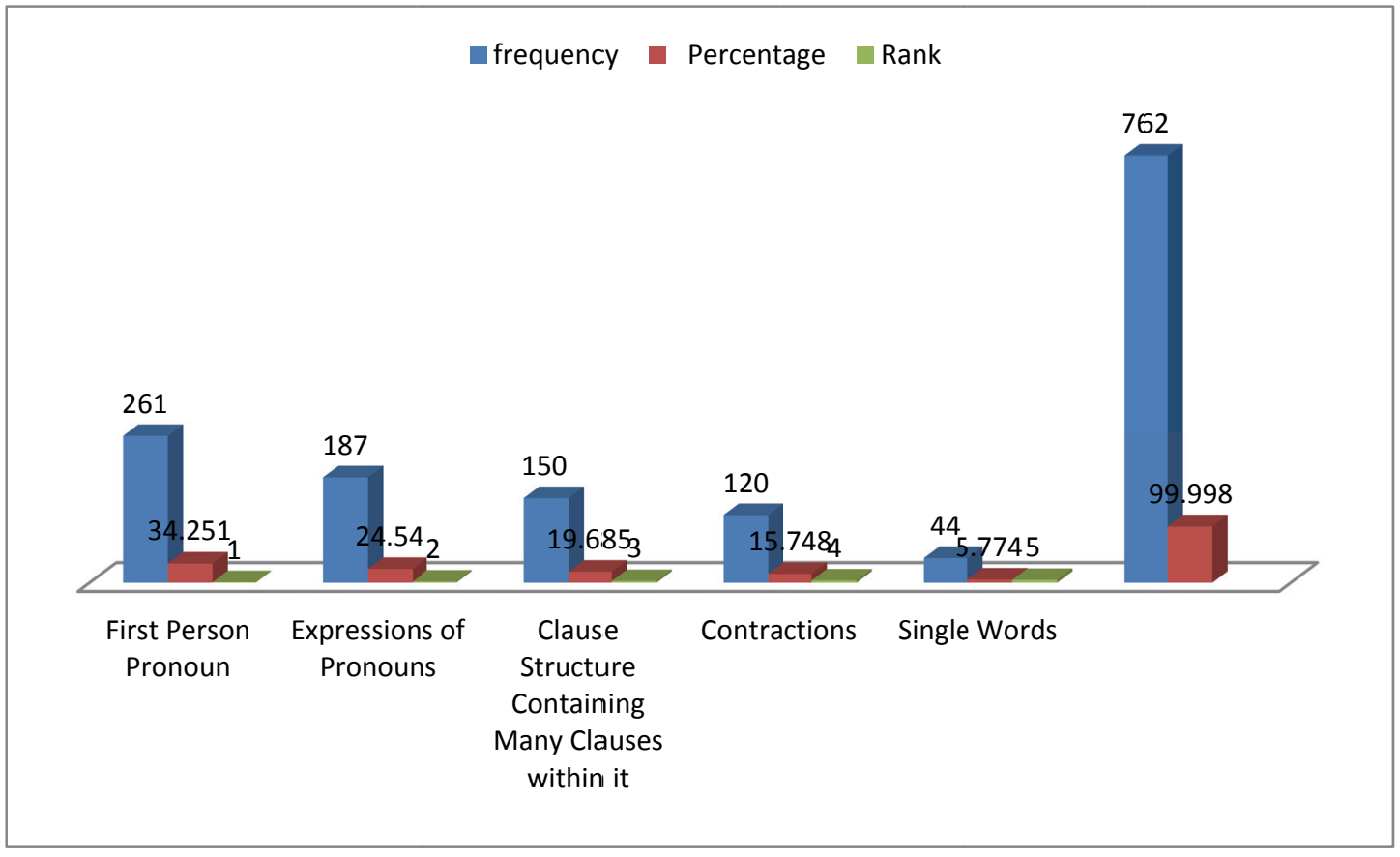

Figure 2. The hierarchical order for frequency and percentages of register errors

\subsubsection{Errors in the use of first person pronoun}

These errors are the most recurrent ones in this category. The total number of errors here is 261 with a percentage of 34.251 . 
(1)* We must do anything to help our parents... We must help our parent and remember what they did to us when we are children... We must do anything to make them happy.

(2)* I refuse that English language should be the national language of my country... Our language is Arabic. That is why, we should refuse...

The examples above, which are written by the subjects, should be written as it follows:

- Helping the parents is one of the sons' duties towards their parents...

- Arabic is the national language of Iraq. Other languages such as English cannot be the national language the country...

\subsubsection{Errors in the use of expressions of pronouns}

These errors occupy the second rank in this category. Their total number is 187 with a percentage of 24.540 .

(3)* My opinion is Iraq needs to make English as a national language beside Arabic, because our country needs to contact with other countries...

(4)* I think that belief is false because the grades encourage the student to develop his level... The examples above, which are written by the subjects, should be written as it follows:

- Iraq needs to make English as a national language beside Arabic, because any country needs to contact with other countries...

- That belief is false because the grades encourage the student to develop his level...

\subsubsection{Clause structure containing many clauses within it}

These errors occupy the third rank in this category. Their total number is 150 with a percentage of 19.685 .

(5)* The parents usually encourage their sons to complete their study and to be successful persons in the future.

(6)* When the students get a high marks in the exam, this encourages them to work hard in order to take a higher marks but when the teachers give...

The examples above should be written as it follows:

- The parents usually encourage their sons in their study because this makes their sons successful persons in the future.

- Getting a good mark, in the exam, will encourage the students to study hard next exam.

\subsubsection{Contraction}

These errors occupy the fourth rank in this category. Their total number is 120 with a percentage of 15.748 .

(7)* When they become old I didn't let them because my parents give me love and...

(8)* I'll give him a care which means... I'll tired to make her happy.

\subsubsection{Single words}

These errors occupy the sixth rank in this category. Their total number is (44) with a percentage of 5.774. The following examples are the subjects' errors in this category.

$(9)^{*}$ No, I don't agree that English be national language of Iraq because when...

$(10)^{*} Y e s$, of course, I agree with the opinion to encourage learning...

\subsection{Discussion of Results (Explanation of Errors)}

The data show that a large number, that is, thirty-seven, i.e., (92.5\%) of the subjects use first person pronouns in their writings. (See Table 1). As has been indicated in the preceding section, the most frequency errors, in the subjects' writings, are in using first person pronouns. That is why, the total frequency of these errors is (261), i.e., (34.251) in the subjects' writings. Bakir and Lazims' study (2003:11) indicate some errors, which are committed by students, are either attributed to their incompetence in English, or to their unawareness of rules of English essay writing (see examples $(1),(2)$ ). As result shows, many subjects commit errors in using expressions of pronoun (i.e., (31), that is, $(77.5 \%)$ and clause structure (i.e., (29), that is, (62.5\%)). This may due to the subjects' poor writing and their lacking of reading authentic texts (Ahmed, 2011:205). That is why, the total frequency of the errors is (187), i.e., (24.540\%) in the written products from the Iraqi EFL students at Thi-Qar university, College of education. (see examples (3), (4), (5) and (6)). Thus, the first hypothesis which states that, 
incompetence in using and writing English appropriately is potentially the major possible source of the register errors, is accepted.

Register errors also include the need to distinguish between oral and written styles. These two types of writings have their own conventions (Flower, 1966:65). In written style, a number of elements of oral style should not be used such as contractions in English. However, the data demonstrate that (24), i.e., $(60 \%)$ of the subjects use contractions in their writing. That is, the total frequency of their use of contractions is (120), i.e., (15.748) in writing (See examples (7), and (8)). Similarly, (11), i.e., (27.5\%) of the subjects use single words in their writings because of their mixing oral and written styles in their writings. These two types of writings have their own conventions .In oral style, e.g., you can answer on the question of someone by using "yes" or "no". It is, however, wrong to do the same in written style. The subjects' total frequency of single words is (44) with a percentage of (5.774) (See Table 2). Thus, the second hypothesis, which states that most Iraqi English students are unable to distinguish between oral and written styles, is accepted.

\subsection{Conclusion}

Many EFL students fall in register errors as result of inability of distinguishing between their oral and written performance. In this way, this study is designed to explore the different types of register errors in Iraqi EFL students' writings. This is a really challenging, since there are very few works in this area. The findings have then presented the register errors in the students' written products and their possible corrections. Six categories are studied to determine how the subjects tend to use them inappropriately (i.e., informally) in their writing. Using English properly entails appropriate choices in formality. However, the limited knowledge of the main characteristics of good English writing (i.e., formal English) seems clear in the students' writing products in the findings of this study. The results of the study indicate most Iraqi EFL student are incompetents in writing English appropriately and unable on distinguishing between oral and written style (e.g. when their teachers ask them to write about a certain topic). Also they make indiscriminate use of different elements which belong to different types of register. That is why, they fall in register errors.

Evaluating the performances of such system is necessary but raises many problems, in particular due to the difficulty of detecting and analyzing errors: our linguists disagree from time to time: this motivates our interactive approach where the student gets arguments for or against a certain correction.

\subsection{Recommendations}

The syllabus designers and the textbook writers should revise the composition and essay syllabus and textbooks by devoting some chapters including how to write English in an appropriate and good way. To do this, more details and examples must be provided in the syllabus referring to a number of oral style elements should not be used such as contractions in written style. In order to prepare students with a good amount of knowledge concerning different kinds of languages, syllabus designers are required to include materials under the title 'language situations. By doing this, the syllabus designers will indicate the differences between oral style and written style.

\section{References}

1. Ahmed, H.A.(2011). The EFL Essay Writing Difficulties of Egyptian Student Teachers of English: Implications for Essay Writing Curriculum and Instruction. University of Exeter. Available on: https://ore.exeter.ac.uk/ repository/handle/10036/120146

2. Al-qaraghooly, D.and Sultan,M.(2008). An Error Analysis of the Scientific Writing of Iraqi EFL Postgraduates at the University of Technology. Available on: http://www.iasj.net/iasj?func=fulltext\&aId=32358

3. Al-Samarrai, Intisar I. (2003) .The Effect of Using Certain Teaching Techniques on Overcoming Linguistic Difficulties Faced by Postgraduate Students in Comprehending Scientific Texts in English. Unpublished Ph.D. Dissertation, University of Baghdad.

4. Baker, M. (1992) In Other Words: A Course book on Translation. New York: Chapman and Hall, Inc. 
5. Bakir, H. and Lazims,G. (2003).Stylistic Problems Confronting Arab Students in Arabic-English Translation .Iran. Ajman University of Science and Technology UAE.

6. Biber, D. (1995). Dimensions of register variation: a cross-linguistic comparison. Cambridge: Cambridge University Press.

7. Brochure,G. (2006). Communicating and Learning in Engineering Online Resources. Monash University. Available on: http://www.eng.monash.edu.au/current- students/download/improving-scientific-writing-style.pdf

8. Chuquet, H., Paillard, M. (1989 ). Approche Linguistique des Problèmes de Traduction, Paris, Ophrys.

9. Corder, S.Pit (1973) .Introducing Applied Linguistics. Harmondsworth, Middlesex: Penguin Education.

10. Damen (2002). Informality. Available on http://www.usu.edu/markdamen/writingguide/01inform.htm

11. Devlin, J. and Waters, T. (2007) How to Speak and Write Correctly .Available on: http://www.sepo.net/ books/english-grammar/letter-writing/

12. Ellis, Rod (1994) The Study of Second Language Acquisition. Oxford: Oxford University Press (7th impression, 2000).

13. Flower,R.,ed.(1966).Essay on Style and Language .London: Routledge and Kegan Paul. Hammadou, J.,(2000) the Impact of Analogy and Content Knowledge on Reading Comprehension: What Helps, What Hurts, ERIC. Available on: http://farnasfaisal.wordpress.com/2013/04/29/book-review-investigating-english-styledavid-crystal-and-derek-davy-london-longman-1969-264-pages/

14. Hudson, G. (2000). Essential introductory linguistics. Malden, Mass: Blackwell Publishers.

15. Prakken, H., (2006). Formal systems for persuasion dialogue, Knowledge Engineering Review. Vol.(21), No.(2), PP:163-188.

16. Tchudi (1990). Stylistics. Oxford: Oxford University Press

17. Vinay, J.P., Darbelnet, J., (1963). Stylistique Comparee du Francais et de 'Anglais, Paris, Didier. 


\section{Appendix}

Sample of the Students' Writing

(1) In my nind I think that grades . help the students tosucessed in exane. Because these grades make the student work hand ts $=$ iset their successeful. Therefore, I $=1,=5$ d agree with holping the student's abecause the students in the college when . They find someone cares for their future. They:donetry " fo foil his hoping and they - cearry the repect to the tearher because when they donzt care for their future, the tracher interests and $i=$ works anything for them. Thurefores I agree with helping the students somative 20

Iclam is sur velejious, - Ourreleglows advises

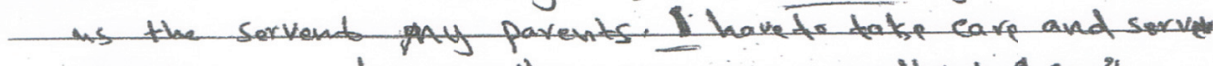
woy parants because thesy gave me many thing 1 can't count thom. Therefor, we book the children live without parentos. fuffor in = their: tife from many things DThankmy God becouse did prevent me from them. I I thank there is net similar between what they do for ane and Whot 1 do for them. lask $M y$ Gad doer not take my soul and? does net work pay duty to my paremb

This Antter is very importan but 9 dan't have more lime to wrimo more therefory, a stop heven 